of the train by means of a token which he carries through the section. In Great Britain, tablets, staffs and keys are used as tokens, but the ball token is often used elsewhere. Every single track section equipped for token operation has installed at each end of the section a token instrument containing a supply of tokens. By means of a wire the two instruments are electrically connected and so interlocked that only one token at a time can be inserted, thus ensuring absolute safety. The tokens used in adjacent sections are of different type, and this provides an additional safeguard. When single line sections have outlying sidings or branch lines into which trains can be moved, it is sometimes necessary, and during operation it may be desirable, to clear the section for traffic ; in this case a subsidiary instrument is placed at the siding into which the section token can be placed after the section has been cleared and the siding points reset for the main line.

\section{Reworking Gold Mines}

THE high price of gold has had the effect of causing rapid development of the gold mining industry. In many mines it has been found highly profitable to re-treat old tailings and to mine a much larger proportion of low grade ore. This is illustrated by the Champion Reef Mine situated in Mysore, one of the principal goldfields of India. The finding of ancient workings led to the discovery of the field in 1882 . The ancients with crude appliances got to a depth of about $200 \mathrm{ft}$. When they raised the ore they heated it and threw cold water on it, rendering it friable so that the gold could be extracted by hitting it with a piece of hard rock. The water that accumulates at the bottom of the mine must have been baled out by large gangs of workmen carrying it in vessels. An account of an electric winder for this mine is given in the G.E.C. (General Electric Co.) Journal of November. It is capable of hoisting a load of $5,300 \mathrm{lb}$. of ore from a vertical depth of $3,633 \mathrm{ft}$. with a rope speed of $1,910 \mathrm{ft}$. a minute. The winding motor is rated at 1,150 horse-power. Very complete safety arrangements are made to safeguard the working of the winder. Compared with the steam engine it replaced, a substantial saving has been effected in hoisting costs. The saving is at the rate of $£ 8,000$ a year and this compares very favourably with the total all-in costs of the new electric winder, which was less than $£ 28,000$.

\section{Medical Uses of Radium}

In a report issued by the Medical Research Council (Special Rep. Series, No. 204. London: H.M. Stationery Office. 1s. net), an account is given of the research work done during 1934 with radium and radium emanation distributed to selected centres in Great Britain and Ireland, and it continues the accounts given in the twelve previous similar reports. In the earlier pages, the experimental work carried out at the Imperial College of Science and elsewhere is summarised. Then follow the clinical reports upon the treatment of various forms of cancer and also of some non-malignant conditions. In addition, statistical data are given relating to the afterhistories of patients treated in previous years for cancer of the breast, uterus, rectum, mouth and adjacent structures. These data are somewhat depressing, for they show a large mortality; for example, of 169 cases of cancer of the rectum treated in the six years, 1925-30, only 21 are now living. It must be remembered, however, that most of the cases were at an advanced stage, and the data are also incomplete in that they do not indicate the number of patients who may have died as a result of disease other than an extension or recurrence of the cancer.

\section{Vital Statistics for the Year I934}

We have received the Registrar-General's Statistical Review of England and Wales for the Year 1934 (Tables. Part 1. Medical. London : H.M. Stationery Office. $6 s$. net). The estimated population for the mid-year was $40,467,000$, females exceeding males by nearly a million and a half. Data are given for the last ten years, and in the case of diabetes and pernicious anæmia, the medical treatment of which has made great progress in the last few years, the death-rates per million living were respectively 110 and 65 in 1924, and 160 and 59 in 1934. The deathrate from pernicious anæmia has, therefore, declined, but not that from diabetes, which now appears to be more particularly fatal among elderly females. The death-rate from cancer and tumours was per million 1,363 in 1924 and 1,635 in 1934 , the increase being more marked in the male sex. Motor-vehicles accounted for 7,156 deaths, of which nearly one third occurred at the age $20-30$ years.

\section{National Institute of Industrial Psychology}

Is the fifteenth Annual Report of the National Institute of Industrial Psychology, the problem of vocational guidance is given prior place, and evidence is produced of the increasing recognition by bodies concerned with the placing of young people of the desirability of using scientific knowledge when advising them, instead of leaving the choice to chance or the vagaries of people ignorant of the problem. Recent developments indicate a growing interest in this aspect of the Institute's work. In addition, investigations have been continued for a number of firms into problems concerned with factory and office organisation, selection of staff, marketing and the standardisation of tests. Lectures have been given in different towns in order to interest and inform industrialists about the importance of the workers of the machines as well as of the machines. The Report concludes with an account of the Institute's financial position.

\section{Register of Tuberculosis-free Herds}

THE first "Register of Attested Herds" under the Tuberculosis (Attested Herds) Schemes for England and Wales and for Scotland has been issued jointly by the Ministry of Agriculture and Fisheries, London, and Department of Agriculture for Scotland, Edinburgh. The issue of a certificate of attestation is 